\title{
Correction to: Being the Other in Inuit Society
}

\author{
Anja Nicole Stuckenberger
}

\section{Correction to:}

Chapter 4 in: J. D. M. Platenkamp, A. Schneider (eds.), Integrating Strangers in Society, https://doi.org/10.1007/978-3-030-16703-5_4

The original version of the chapter- 4 was inadvertently published with a wrong affiliation. This has been corrected now and email address for the author has been included in the proofs.

The updated original online version of this chapter can be found at https://doi.org/10.1007/978-3-030-16703-5_4

(C) The Author(s) 2019 